\title{
Handle analysis of Cosmetic Textiles and its Correlation with Subjective Characteristics -Focus on puff textile-
}

\author{
Cheul Sun Jung ${ }^{1)}$ and Young Seok Koo ${ }^{2) \dagger}$ \\ ${ }^{1)}$ Subdivision of Cosmetology, KyungNam College of Information \& Technology; Busan, Korea \\ ${ }^{2)}$ Dept. of Clothing \& Textiles, Pusan National University; Busan, Korea
}

\begin{abstract}
This study examined the correlation between a handle evaluation of cosmetic puff textile and a sensory evaluation. The KES-F system was used to analyze the main mechanical factors for the handle evaluation and a statistical method was used for the sensory evaluation. The results revealed different mechanical properties and handle values of the tested cosmetic puff textiles. A material type and structure of the cosmetic textile affected the handle property of the material which is the most important factor for a cosmetic purpose. Particularly, the physical properties of textile material are likely to be important factors for the sensory property of cosmetic material. In addition, the sensory evaluation also revealed different sensory characteristics of the cosmetic efficiency according to the cosmetic puff textile. No close relationship was observed between the mechanical properties and sensory evaluation on the cosmetic puff textiles. The sensory evaluation of a cosmetic efficiency is not only decided by the physical and mechanical characteristics of the cosmetic textile material. Overall, when using textiles used for the cosmetic purposes, it is important to consider not only the proper mechanical properties of the textiles but also the use and sensory satisfaction. Development and selection of the cosmetic textiles should be focused on both the material function and consumer satisfaction.
\end{abstract}

Key words : cosmetics, puff, handle, KES, sensory

\section{Introduction}

Cosmetology is not only a tool for expressing beauty but also for improving the outlook of an individual because it is important to express self-image and satisfaction in psychological aspects. Accordingly, the cosmetic industry has developed a range of products according to the life style and value criteria of consumers. In particular, consumers demand high functional cosmetic materials based on the conventional concept of luxury and functional variety as a tool for expressing beauty in the contemporary cosmetic industry(Lee, 2006).

Textiles play a role in many functional cosmetic products. The textiles used for cosmetic materials are selected mainly for skin touch. On the other hand, there have been no evaluations of the sensory characteristics of many cosmetic textiles currently used, and many cosmetic items are produced according to the manufacturer's choice.

In the textile industry, many studies(Howorth \& Oliver, 1958; Kim \& Na, 2000; Kim \& Kim, 1985; Kwang, 1984; Kwon \& Kwon, 2009; Na, 1999; Shin \& Kim, 2000) have carried out objective sensory evaluations of textile products and a handle evaluation is used widely for objective evaluations of the textile products.

$\dagger$ Corresponding author; Young-Seok Koo

Tel. +82-51-510-2843, Fax. +82-51-583-5975

E-mail: youngskoo@pusan.ac.kr
Fabric handle is the way a fabric feels when it is touched and manipulated by hand. Through the touch and feel of fabric and with little experience, people can gain information that no other testing technique could fully yield.

The handle is a sensory property of fabrics, such as touch and sight, and is affected by the subjective sensory characteristics of the evaluator. Therefore, it is difficult to obtain a reliable and objective evaluation.

To overcome this disadvantage, statistical and objective analysis of the handle were carried out according to the mechanical and sensory characteristics of fabrics(Howorth \& Oliver, 1964; Kawabada, 1980; Kim \& Park, 1984). KES-F(Kawabata Evaluation System for Fabric) was developed by Kawabata and Niwa in 1970 based on previous studies, which is used widely for an evaluation of the fabric handle using the mechanical and sensory data of fabrics. The KES-F system is a tool for evaluating the touch sensation of fabrics using a variety of mechanical properties, such as the tensile, shear, bending, compression and surface properties of fabrics. The H.V. (Handle Value) and T.H.V. (Total Handle Value) of fabrics based on the mechanical properties are also evaluated by this system. Therefore, the KES-F system is an objective system for examining the characteristics of fabrics by statistical methods using the mechanical and sensory properties of fabrics instead of a subjective evaluation of the fabric handle(Ajayi \& Elder, 1997; Ellis \& Garnsworthy, 1980; Kim \& Lee, 1997). Evaluating the fabric han- 
dle for consumers is very important in terms of the sensory characteristics because the subjective experience on the quality of a product is essential for selecting fabric products.

In the development and application of cosmetic products, it is important to examine the fundamental properties of cosmetic materials affecting the sensory characteristics by analyzing the interaction of the subjective sensory and mechanical properties of cosmetic materials. This is because the mechanical properties, such as compression and friction, and the physical properties, such as structure and surface type of material, affect the characteristics of the cosmetic product, such as touch, smoothness, softness, etc.

Touch is an important human sense when skin and fabric come in contact, in which a range of physical interactions affect the final decision of touch. In particular, because a good interaction between sensitive skin and fabric is essential for cosmetic products, it is necessary to study the interaction of the objective properties and touch sensory of cosmetic materials. In the aforementioned aspect, an objective handle evaluation of the cosmetic materials is necessary with the KES-F system.

In this study, cosmetic puff fabric, which is used widely in the cosmetic products, was analyzed by an objective handle evaluation and a subjective sensory evaluation based on the mechanical properties and the interactions with the subjective sensory characteristics. This study provides objective and fundamental data to select and apply textile materials to the cosmetic products.

\section{Experimental}

\subsection{Specimen and test method}

Eight different types of plush fabrics that are used widely for cosmetic puff textiles were used as the specimens. The mechanical properties of the specimens were evaluated using the $\mathrm{KN}-101-\mathrm{W}$ equation for the primary handle value (Koshi, Numeri, Fukurami) and KN301-W for the Total Handle value (T.H.V.) based on the MEN'S WINTER SUIT program in the KES-F system. The bending property in the test items was not measured due to the specimen thickness, which exceeded the clamping width in the measuring device.

\subsection{Subjective sensory test}

Twenty five females in their 20 's were selected for the subjective
Table 1. Characteristics of the fabric mechanical properties

\begin{tabular}{|c|c|c|c|}
\hline $\begin{array}{l}\text { Mechanical } \\
\text { properties }\end{array}$ & $\begin{array}{c}\text { Characteristic } \\
\text { value }\end{array}$ & Remarks & Units \\
\hline Tensile & $\begin{array}{l}\text { LT } \\
\text { WT } \\
\text { RT }\end{array}$ & $\begin{array}{l}\text { Linearity } \\
\text { Tensile Energy } \\
\text { Resilience }\end{array}$ & $\begin{array}{c}- \\
\mathrm{g} \cdot \mathrm{cm} / \mathrm{cm}^{2} \\
\%\end{array}$ \\
\hline Bending & $\begin{array}{c}\mathrm{B} \\
2 \mathrm{HB}\end{array}$ & $\begin{array}{l}\text { Rigidity } \\
\text { Hysteresis }\end{array}$ & $\begin{array}{l}\mathrm{g} \cdot \mathrm{cm}^{2} / \mathrm{cm} \\
\mathrm{g} \cdot \mathrm{cm} / \mathrm{cm}\end{array}$ \\
\hline Shearing & $\begin{array}{c}\mathrm{G} \\
2 \mathrm{HG} \\
2 \mathrm{HG} 5\end{array}$ & $\begin{array}{l}\text { Shear stiffness } \\
\text { Hysteresis at }=0.5^{\circ} \\
\text { Hysteresis at }=5^{\circ}\end{array}$ & $\begin{array}{l}\mathrm{g} / \mathrm{cm} . \text { degree } \\
\mathrm{g} / \mathrm{cm} \\
\mathrm{g} / \mathrm{cm}\end{array}$ \\
\hline Compression & $\begin{array}{l}\mathrm{LC} \\
\mathrm{WC} \\
\mathrm{RC}\end{array}$ & $\begin{array}{l}\text { Linearity } \\
\text { Energy } \\
\text { Resilience }\end{array}$ & $\begin{array}{c}- \\
\text { g.cm } / \mathrm{cm}^{2} \\
\%\end{array}$ \\
\hline Surface & $\begin{array}{l}\text { MIU } \\
\text { MMD } \\
\text { SMD }\end{array}$ & $\begin{array}{l}\text { Coefficient of friction } \\
\text { Mean deviation of MIU } \\
\text { Geometrical roughness }\end{array}$ & $\begin{array}{c}- \\
- \\
\text { micron }\end{array}$ \\
\hline Thickness & $\begin{array}{l}\mathrm{T} \\
\mathrm{W}\end{array}$ & $\begin{array}{l}\text { Thickness at } 0.5 \mathrm{~g} / \mathrm{cm}^{2} \\
\text { Weight per unit area }\end{array}$ & $\underset{\mathrm{mg} / \mathrm{cm}^{2}}{\mathrm{~mm}}$ \\
\hline
\end{tabular}

sensory test. The sensory and utility characteristics of the cosmetic puff textile were evaluated using the 5 point Likert scale. The subjects are considered to be an optimum evaluating group because they have sensitive touch feeling and frequently use cosmetic products. A survey questionnaire consisting of 6 sensory items, such as mechanical feeling (soft, stimuli, elasticity, tenacity) and make-up utility (skin contact and detach of cosmetic powder), was given to the subjects.

\subsection{Correlation evaluation}

Correlation analysis of the mechanical properties was performed using the KES-F system. Moreover, the correlation of the mechanical properties with the primary handle value and total handle value was also analyzed. Items in the subjective sensory test and objective handle test were also analyzed for the correlation.

\section{Results and Discussion}

\subsection{Tensile property}

Fig. 1 shows the tensile characteristics of 8 specimens of puff textiles. Most specimens except for S8 showed extension in the warp direction because the linearity results showed lower values in the

Table 2. Specifications of the specimen

\begin{tabular}{|c|c|c|c|c|c|c|c|c|}
\hline Name & S1 & $\mathrm{S} 2$ & S3 & S4 & S5 & S6 & S7 & S8 \\
\hline Specimen type & ITY & ITY2.0 & velvet & new poly & new poly & boa & Micro fiber & cotton \\
\hline Fabric structure & plush & plush & plush & plush & plush & plush & plush & plush \\
\hline $\mathrm{T}(\mathrm{mm})$ & 2.36 & 2.29 & 3.02 & 2.30 & 3.19 & 5.36 & 3.38 & 4.17 \\
\hline $\mathrm{W}\left(\mathrm{mg} / \mathrm{cm}^{2}\right)$ & 31.59 & 30.82 & 46.66 & 33.99 & 33.10 & 45.61 & 31.44 & 27.63 \\
\hline
\end{tabular}



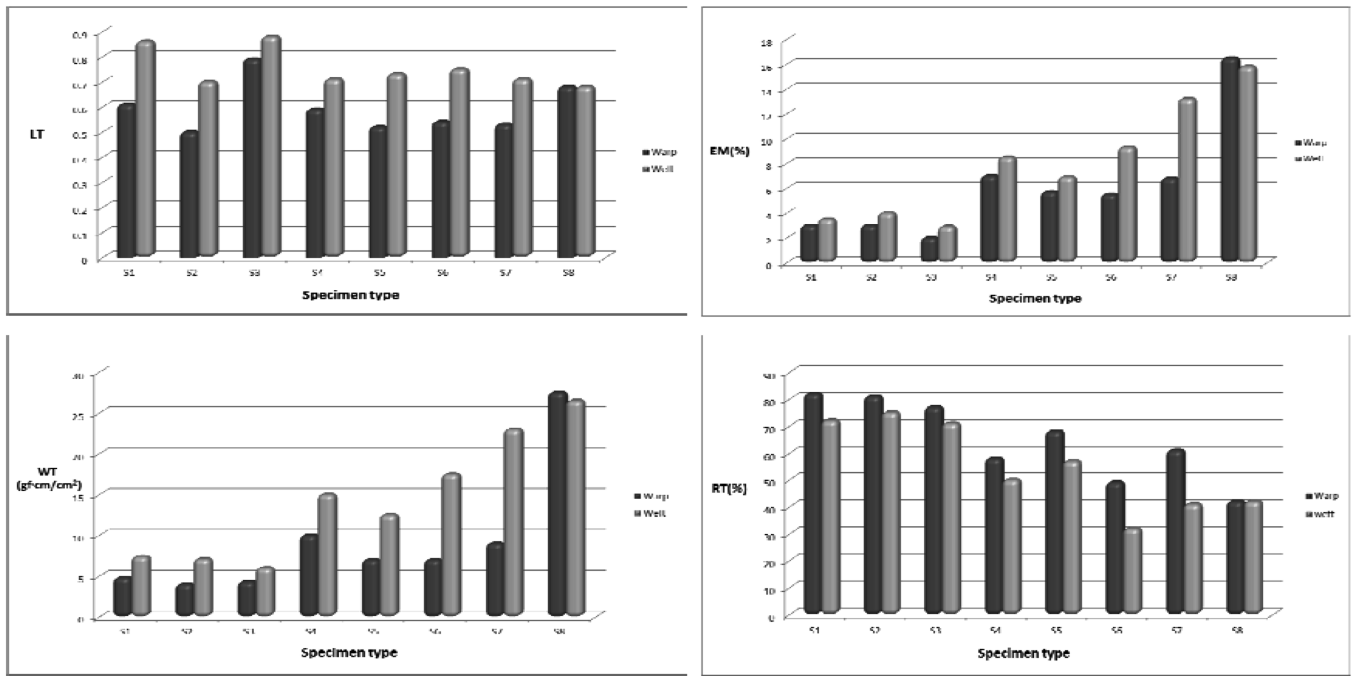

Fig. 1. Tensile properties.

warp direction than weft. S2 showed the lowest linearity in the warp direction but $\mathrm{S} 8$ showed the lowest linearity in the weft direction.

Most specimens except for S8 showed high tensile energy in the weft direction. S8 showed a high tensile energy in both the warp and weft direction. Most specimens showed similar resilience except for S8, which had the lowest resilience. The warp direction had better resilience than the weft direction. In the case of extensibility, S6 and S7 showed a significant difference in the warp and weft directions but most specimens were similar. Therefore, there were no distinct differences in the warp and weft directions of the puff textiles but a slight difference among specimens in the tensile test.

\subsection{Shear property}

Fig. 2 shows the results of the shear test, which is one of the
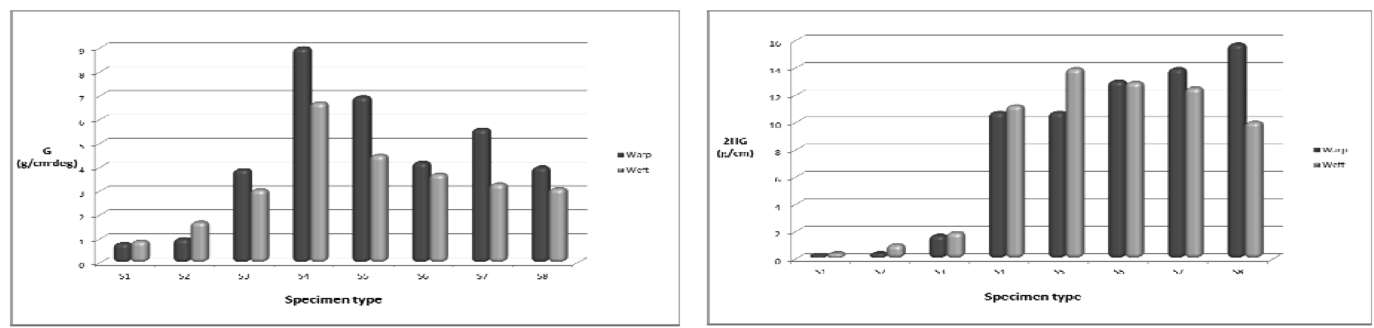

important mechanical properties for fabric flexibility. The shear stiffness was high in the warp direction in most specimens. Moreover, the warp direction was stiffer than the weft direction. S4 had the highest shear stiffness, indicating no easy deformation.

Slight differences in shear hysteresis with the shear angle in the warp and weft directions were observed. Among the specimens, S8 had high shear hysteresis in the warp direction and the highest value in the weft direction. S8 also showed the highest shear hysteresis in the 2HG5 results, which meant easier deformation than the other specimens.

\subsection{Compressibility}

Fig. 3 shows the results of the compressibility. S7 and S8 showed

high compression linearity but S3 and S6 showed a low value,

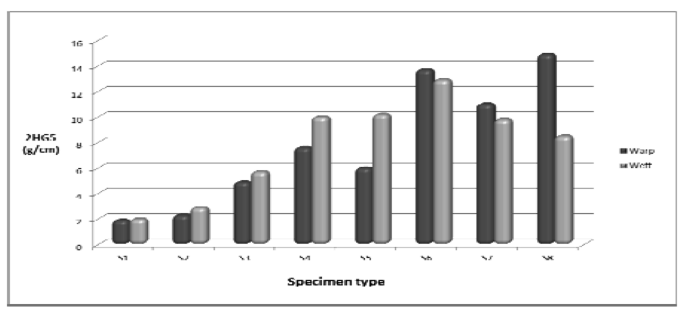



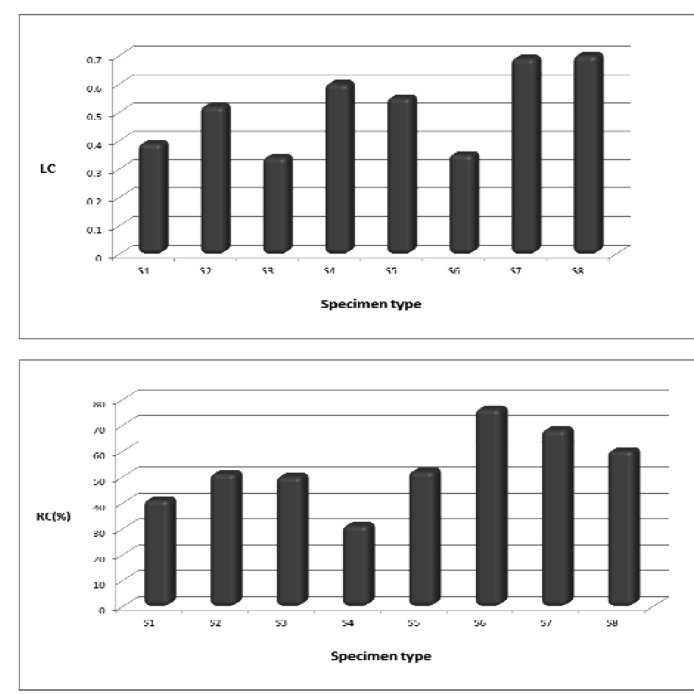

Fig. 3. Compression properties.

which indicates easy initial compression and soft to the compression. S4, S5, S6, S7 and S8 had high and similar compressional energy but S1, S2 and S3 had low compressional energy, which means soft and abundant compressional resilience. S6 had the highest compressional resilience, followed in order by S7 and S8. S4 had the lowest value among the specimens. S1, S2 and S3 had very soft surface fibers according to the results of the compressional energy. S7 and S8 contained surface fibers that were slightly stiff but resilient. S6 had soft and good resilient fibers on the surface.

\subsection{Surface properties}

Fig. 4 shows the surface characteristics in terms of the softness and smoothness of the fabric. Most specimens had a MIU (coefficient of

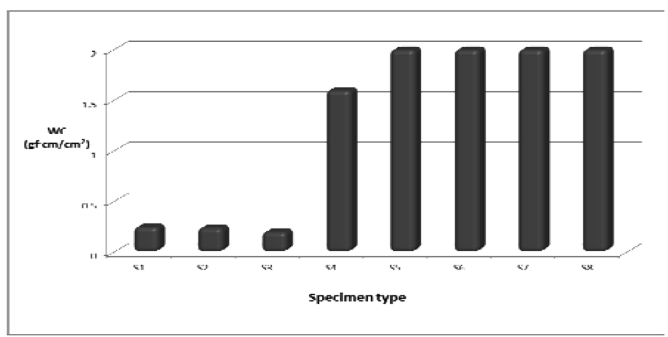

friction) of 0.3 and 0.4 , which was similar in the warp and weft directions except for $\mathrm{S} 1$ and $\mathrm{S} 8$. The surface fibers of the cosmetic puff textiles consisted of a similar fiber structure, which did not affect the frictional characteristics in the warp and weft directions.

S1 and S8 had higher MIU and MMD values than the other specimens, and were regarded as having stiff fibers on the surface. $\mathrm{S} 1$ and S8 also showed a large difference in SMD in the warp and weft directions, which appeared to have a large deviation in length and thickness of the surface fibers.

Fig. 4 revealed slight differences in the measuring wave among the specimens. The friction coefficient was similar in the forward and backward directions but $\mathrm{S} 1$ and $\mathrm{S} 8$ had high surface frictional coefficients. S1, S2, S3 and S8 showed a large wave change in
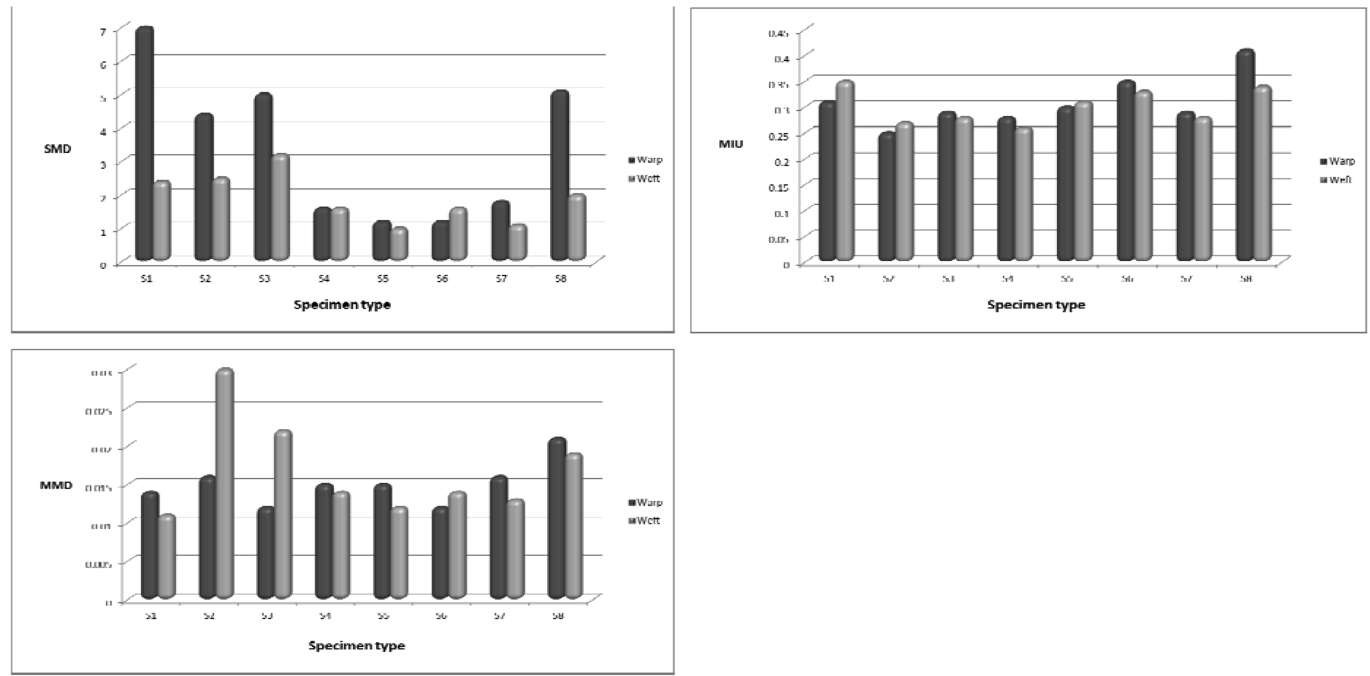

Fig. 4. Surface properties. 

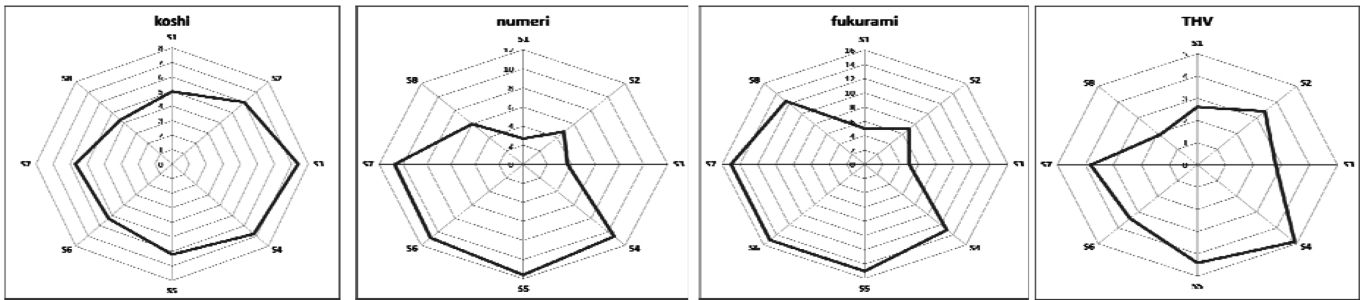

Fig. 5. Primary handle value and total handle value.

thickness but S4, S5, S6 and S7 showed a small change, which meant a low variation of surface fibers and even surface fineness.

\subsection{Handle property}

Fig. 5 shows the primary and total handle value of the specimens. Koshi represents the stiffness of a fabric as a sensory value based on the resilience and elasticity of a fabric. S3, S4 and S5 showed slightly high Koshi values but S8 showed the lowest value, and appeared to have soft fibers in the structure.

Numeri represents the smoothness of a fabric, and is a sensory value based on the smooth, flexible and soft characteristics of a fabric. S4, S5, S6 and S7 had high Numeri values, and were softer and smoother than the other specimens.

Fukurami represents the fullness $\&$ softness of a fabric, and is a sensory value based on the compressional resilience and thickness. S4, S5, S6, and S7 showed high Fukurami values, which had better volume and softness than the other specimens. S4 showed the highest total handle (T.H.) value followed by S5. S6 and S7 also had a higher T.H. value than the average.

\subsection{Correlation analysis of the mechanical properties}

Table 3 lists the correlation among the mechanical properties of the specimens. The correlation coefficient between the surface property of the MIU and Koshi was -0.72 with $5 \%$ statistical significance.

The Numeri showed a significant correlation with the shear properties, and the WC also showed high correlation with the compressional property. On the other hand, the surface property of MMD and SMD showed a high negative association with the Numeri.

In the case of Fukurami, the shear property of 2HG and 2HG5, and the compressional property of WC showed a strong correlation. On the other hand, the tensile property of RT and the surface property of MMD and SMD showed a negative correlation. The shear property of $\mathrm{G}$ showed a positive correlation and the surface property of MMD and SMD showed a negative correlation.

A comparison of the P.H.V correlation revealed Fukurami and Numeri to have very strong correlation. Therefore, the characteristics of cosmetic puff textiles, such as freshness, flexibility and

Table 3. Correlation of the mechanical properties and handle value

\begin{tabular}{|c|c|c|c|c|c|c|c|c|c|c|c|c|c|}
\hline & $\mathrm{EM}$ & WT & RT & G & $2 \mathrm{HG}$ & $2 \mathrm{HG} 5$ & MIU & MMD & SMD & $\mathrm{LC}$ & $\mathrm{WC}$ & $\mathrm{RC}$ & Numeri \\
\hline WT & $.99^{* *}$ & 1 & & & & & & & & & & & \\
\hline RT & $-.81^{*}$ & $-.81^{*}$ & 1 & & & & & & & & & & \\
\hline G & .32 & .29 & -.53 & 1 & & & & & & & & & \\
\hline $2 \mathrm{HG}$ & $.71^{*}$ & .684 & $-.88^{* *}$ & $.825^{*}$ & 1 & & & & & & & & \\
\hline 2HG5 & $.75^{*}$ & $.74^{*}$ & $-.98^{* *}$ & .57 & $.87^{* *}$ & 1 & & & & & & & \\
\hline MMD & -.11 & -.06 & .46 & $-.76^{*}$ & -.66 & -.56 & .43 & 1 & & & & & \\
\hline SMD & -.29 & -.23 & .62 & $-.75^{*}$ & $-.82^{*}$ & -.67 & .19 & $.90^{* *}$ & 1 & & & & \\
\hline LC & $.75^{*}$ & $.71^{*}$ & -.41 & .37 & .56 & .34 & -.00 & -.20 & -.32 & 1 & & & \\
\hline WC & $.76^{*}$ & $.73^{*}$ & $-.89^{* * *}$ & .63 & $.94^{* * *}$ & $.90^{* * *}$ & .35 & -.58 & $-.80^{*}$ & .55 & 1 & & \\
\hline $\mathrm{RC}$ & .37 & .37 & -.55 & -.17 & .25 & .61 & .42 & -.25 & -.31 & .00 & .47 & 1 & \\
\hline $\mathrm{T}$ & .49 & .51 & $-.77^{*}$ & .08 & .47 & $.81^{*}$ & .66 & -.26 & -.36 & -.09 & .61 & $.84^{* *}$ & \\
\hline W & -.44 & -.41 & -.02 & .09 & -.10 & .15 & -.06 & -.30 & -.07 & $-.77^{*}$ & -.16 & .23 & \\
\hline Koshi & -.59 & -.59 & .37 & .43 & -.12 & -.26 & $-.72^{*}$ & -.45 & -.12 & -.33 & -.33 & -.46 & \\
\hline Numeri & .37 & .31 & -.68 & $.78^{*}$ & $.87^{* *}$ & $.72^{*}$ & -.12 & $-.87^{* *}$ & $-.99^{* *}$ & .37 & $.85^{* *}$ & .30 & 1 \\
\hline Fukurami & .63 & .59 & $-.85^{* *}$ & .70 & $.94^{* *}$ & $.86^{* *}$ & .17 & $-.72^{*}$ & $-.91^{* *}$ & .49 & $.97^{* *}$ & .44 & $.94^{* *}$ \\
\hline THV & -.23 & -.29 & -.05 & $.72^{*}$ & .43 & .08 & -.69 & $-.76^{*}$ & $-.74^{*}$ & .13 & .28 & -.31 & $.71^{*}$ \\
\hline
\end{tabular}


Table 4. Factor analysis of the mechanical properties

\begin{tabular}{cl}
\hline Factor & Physical Properties \\
\hline 1 & G, 2HG, Numeri, Fukurami \\
2 & EM, WT, 2HG, 2HG5, MIU, WC \\
3 & RC, T \\
4 & LT, W, Koshi \\
\hline
\end{tabular}

volume, are affected by a range of mechanical properties.

Table 4 lists the results of factor analysis for the T.H.V. of the cosmetic puff textile based on the mechanical properties and primary handle values using the KES-F system.

As shown in Table 4, factor 1 denotes the shear properties, Numeri, and Fukurami. Factor 2 comprises the tensile, shear, surface and compressional properties. Factor 3 denotes the compression and thickness, and factor 4 has the tensile, weight and Koshi properties.

The characteristics of cosmetic puff textile are not expressed by a particular mechanical factor of the material but by a combination of various mechanical properties.

\subsection{Subjective sensory evaluation}

Fig. 6 shows the results of the subjective sensory test. S7 showed the highest soft sense. The other specimen also had values higher than the average except for S6. S3, S7, and S8 showed a good skin stimuli sense. Moreover, S8, S7, and S3 had a smooth feeling to skin touch. $\mathrm{S} 7$ had the best elasticity but most specimens exhibited good elasticity. S8 had the lowest cosmetic feasibility score in cosmetic power detachment, followed in order by S7 and S3. S8 and
S7 had better cosmetic adhesion to the skin, and the other specimens also had suitable skin adhesion.

Table 5 lists the result of correlation analysis in the subjective sensory evaluation. The softness and stimuli of the cosmetic puff textile had a strong interaction, and the stiffness with softness and stimuli had very strong correlation. Cosmetic powder detachment also had a high correlation with stiffness. On the other hand, the correlation between the objective and subjective handle evaluation were very low as shown in table 6 .

\section{Conclusion}

Cosmetic puff textile was analyzed for the interaction between the objective and subjective handle evaluation based on the mechanical properties and subjective characteristics.

Table 5. Correlation of the subjective sensory factors

\begin{tabular}{|c|c|c|c|c|c|c|}
\hline & softness & stimuli & elasticity & stiffness & $\begin{array}{c}\text { powder } \\
\text { detachment }\end{array}$ & $\begin{array}{l}\text { powder } \\
\text { adhesion }\end{array}$ \\
\hline softness & 1 & & & & & \\
\hline stimuli & $-0.89^{*}$ & 1 & & & & \\
\hline elasticity & 0.51 & 0.41 & 1 & & & \\
\hline stiffness & $-0.93^{*}$ & $0.97^{*}$ & 0.42 & 1 & & \\
\hline $\begin{array}{l}\text { powder } \\
\text { detachment }\end{array}$ & 0.62 & 0.69 & 0.56 & $0.73^{*}$ & 1 & \\
\hline $\begin{array}{l}\text { powder } \\
\text { adhesion }\end{array}$ & 0.49 & 0.29 & 0.44 & 0.48 & 0.48 & 1 \\
\hline
\end{tabular}
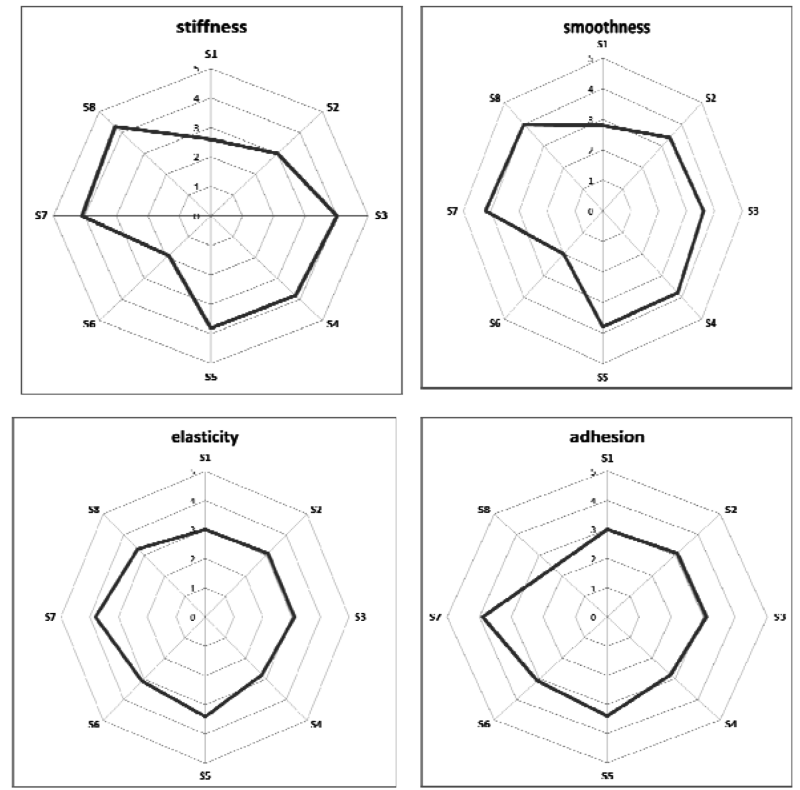
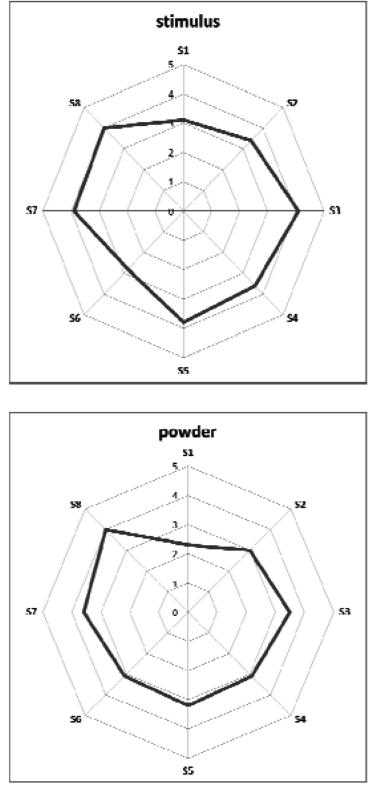

Fig. 6. Results of the subjective sensory test. 
Table 6. Correlation of the subjective and objective sensory factors

\begin{tabular}{lcccccc}
\hline & softness & \multicolumn{2}{c}{ stimuli elasticity stiffness } & $\begin{array}{c}\text { powder } \\
\text { detachment }\end{array}$ & $\begin{array}{c}\text { powder } \\
\text { adhesion }\end{array}$ \\
\hline Koshi & 0.10 & 0.32 & -0.24 & 0.18 & -0.01 & -0.71 \\
Numeri & 0.10 & -0.08 & 0.25 & 0.05 & 0.30 & 0.24 \\
Fukurami & 0.13 & -0.06 & 0.31 & 0.11 & 0.43 & 0.49 \\
T.H.V. & 0.11 & -0.04 & -0.09 & 0.01 & -0.13 & -0.28 \\
\hline
\end{tabular}

The cosmetic puff textiles used in the study had slightly different mechanical properties in expressing the handle value. The different mechanical properties were caused by the fiber type and fineness of the puff textile for different cosmetic use. The structural difference in the puff textile required for maximum cosmetic efficiency in accordance with the cosmetic material was another reason for the difference. Therefore, consumer sensitivity to the cosmetic puff textile is expected to differ according to the characteristics of the puff textiles.

The S4 specimen was the best material in terms of the handle evaluation of clothing in the KES-F system. On the other hand, it was difficult to express the absolute correlation between the objective and subjective handle evaluation, as shown in the result of the subjective sensory evaluation.

The results showed that the subjective sensory decision along with the touch sense was not affected by the physical properties of the cosmetic puff textile.

In cases where the sensitivity of touch to skin is the most important factor for a cosmetic textile material, the material type and structural characteristics are important for maximizing the touch sensitivity to the material. On the other hand, a sensory evaluation of a cosmetic efficiency is not only decided by the physical and mechanical characteristics of the cosmetic textile material.

The cosmetic textiles are expected to evolve with a range of new functional materials in the future. On the other hand, the selection and use of materials for cosmetic purposes should not just focus on the material function but also on the oriented purpose with a profound consideration for maximizing consumer satisfaction.

\section{Acknowledgements}

This work was supported by Pusan National University Research Grant.

\section{References}

Ajayi, J. O., \& Elder, H. M. (1997). Fabric friction, handle, and compression. Journal of Textile Institut, 88 part, l(3), 232-241.

Ellis, B. C., \& Garnsworthy, R. K. (1980). A review of techniques for the assessment of hand. Textile Research Journal, 50(4), 231-238.

Howorth, W. S., \& Oliver, P. H. (1958). Application of multiple factor analysis to the assessment of fabric handle. Journal of Textile Institute, 49, 540,

Howorth, W. S., \& Oliver, P. H. (1964). Handle of suiting, lingerie and dress fabric. Journal of Textile Institute, 55, 251,

Kim, C. J., \& Na, Y. J. (2000). Physical stimulus of silk woven fabrics, subjective hand and mechanical properties. Journal of the Korean Society of Clothing and Textiles, 24(3), 429-439.

Kim, D. L., \& Park, J. H. (1984). A study on the mechanical properties and the handle of fabrics. Journal of the Korean Society of Clothing and Textiles, 8(2), 47-57.

Kim, K. A., \& Lee, M. S. (1997). The assessment of hand for alkaline hydrolyzed polyester fabrics (I) - Development for the subjective hand evaluation scale -. Journal of Korean Fiber Society, 34(4), 232-239.

Kim, T. H., \& Kim, S. J. (1985). A study on the physical properties of textile materials. Journal of the Korean Society of Clothing and Textiles, 9(1), 47-55.

Kawabada S. (1980). The standardization and analysis of hand evaluation (2nd Edition). The textile machineary soceity of Japan.

Kwon, D. Y., \& Kwon, Y. A. (2009). A Study on the physical properties and the handle of silver combined knit. Fashion and Textile Research Journal, 11(4), 641-647.

Kwang, H. S. (1984). A study on the structural conditions and the compressional properties of wool fabrics. Journal of the Korean Society of Clothing and Textiles, 8(3), 67-71.

Lee, Y. H. (2006). A differences in preference and evaluation on the image of make-up (part II) -Focused on perceiver's age \& habitant-. Journal of the Korean Society of Clothing and Textiles, 30(5), 684-698.

Na, Y. J. (1999). Compressional properties of fabrics at low pressure to access real fabric handle. Fashion and Textile Research Journal, l(4), 358-362.

Shin, K. I., \& Kim, J. J. (2000). A study on the handle and texture of artificial suede. Journal of the Korean Society of Clothing and Textiles, 24(1), 128-137.

(Received 25 November 2013; 1st Revised 9 January 2014; Accepted 7 March 2014)

Copyright (C) 2014 (by) the authors. This article is an open access article distributed under the terms and conditions of the Creative Commons Attribution license (http://creativecommons.org/licenses/by/3.0/), which permits unrestricted use, distribution, and reproduction in any medium, provided the original work is properly cited. 